\title{
Influence of Brettanomyces ethylphenols on red wine aroma evaluated by consumers in the United States and Portugal
}

\author{
Megan R. Schumaker ${ }^{\mathrm{a}}$, Mahesh Chandra ${ }^{\mathrm{b}}$, Manuel Malfeito-Ferreira ${ }^{\mathrm{b}}$, Carolyn F. Ross ${ }^{\mathrm{a}, *}$ \\ a School of Food Science, Washington State University, Pullman, WA 99163-6376, United States \\ b Linking Landscape, Environment, Agriculture and Food Research Center (LEAF), Instituto Superior de Agronomia, University of Lisbon, Lisbon 1349-017, Portugal
}

\section{A R T I C L E I N F O}

\section{Keywords:}

Brettanomyces

Sensory evaluation

Volatile phenols

Wine knowledge

Cross-culture

\begin{abstract}
A B S T R A C T
Brettanomyces may add complexity to wine at low concentrations but at high concentrations, can result in objectionable wines. The objective of this study was to determine the concentrations at which consumers from two different locations were able to detect Brettanomyces volatile compounds present in a red wine. A red wine blend, used in both countries, was spiked to create five treatments containing different concentrations of 4-ethylphenol (4-EP), 4-ethylguiacol (4-EG), and 4-ethylcatechol (4-EC) in a 5:1:1 ratio, respectively. These treatments were evaluated by consumers in the United States and Portugal $(n=121)$ using a difference from control test. Consumers were also classified as having low, medium, or high wine knowledge. Among the spiked samples, the greatest degree of difference was found between the second and third treatments, corresponding to reported detection and recognition threshold ranges of 4-EP and 4-EG. For some treatments, consumers from Portugal classified in the medium or high knowledge level reported significantly higher mean differences from the control than those in the low knowledge group ( $\mathrm{p}<0.05$ ). Results demonstrated consumers' ability to detect differences in red wines due to Brettanomyces volatile compounds. Results provide useful context on how wine knowledge and cultural variants may affect the detection of Brettanomyces.
\end{abstract}

\section{Introduction}

Wine faults may be caused by the presence of numerous organisms, with one common spoilage organism being Brettanomyces bruxellensis. The growth of Brettanomyces in a wine may lead to the production of many aroma and flavor compounds, creating what is commonly referred to as a "Bretty wine." While many wine faults may be the result of a number of spoilage organisms, Brettanomyces is currently the only microbial species known to synthesize the volatile compounds resulting in the distinct "Bretty" aroma profile (Loureiro \& Malfeito-Ferreira, 2006; Romano, Perello, Lonvaud-Funel, Sicard, \& de Revel, 2009). Of the many compounds contributing to the complex aroma profile, three frequently reviewed volatile phenols are 4-ethyphenol (4-EP), 4-ethylguaiacol (4-EG), and 4-ethycatechol (4-EC). These compounds are formed through the actions of a decarboxylase enzyme, acting on hydroxycinnamic acids that are part of the non-flavonoid phenol fraction of the phenolic compounds in grapes, followed by a reduction reaction (Fugelsang \& Edwards, 2006; Malfeito-Ferreira, Barata, \& Loureiro, 2009; Suárez, Suárez-Lepe, Morata, \& Calderón, 2007).

Aroma descriptors associated with Brettanomyces include smoky, sweaty, and barnyard. These unpleasant descriptors have the potential to severely alter wine quality (Curtin et al., 2008; Malfeito-Ferreira, 2011; Suárez et al., 2007). First studies reported preference thresholds of 4-EP $(620 \mu \mathrm{g} / \mathrm{L})$ and ratios of 4-EP:4-EG $(10: 1,426 \mu \mathrm{g} / \mathrm{L})$ (Chatonnet, Dubourdieu, Boidron, \& Pons, 1992). With continued studies, threshold values ranges have been reported from $230-650 \mu \mathrm{g} / \mathrm{L}$ for 4-EP, and from 33 to $135 \mu \mathrm{g} / \mathrm{L}$ for 4-EG (Lattey, Bramley, \& Francis, 2010; Nikfardjam, May, \& Tschiersch, 2009; Petrozziello et al., 2014; Wedral, Shewfelt, \& Frank, 2010). Threshold values of 4-EC have been reported at $60 \mu \mathrm{g} / \mathrm{L}, 100-400 \mu \mathrm{g} / \mathrm{L}$, and as high as $775 \mu \mathrm{g} / \mathrm{L}$ in Cabernet Sauvignon specifically (Curtin et al., 2008; Hesford, Schneider, Porret, \& Gafner, 2004; Larcher, Nicolini, Bertoldi, \& Nardin, 2008). While the relatively low sensory perception threshold values for these volatile phenols are suggested to highly contribute to wine aroma, many parameters influence both the determination of these threshold values and the overall liking of wines exhibiting "Brett"-character (Curtin et al., 2008; Petrozziello et al., 2014).

Within the wine industry, the aroma profile incurred by Brettanomyces is a topic of reoccurring debate. At low concentrations, Brettanomyces may positively contribute a leathery aroma to wine, while at high concentrations, the aroma profile is generally considered to negatively impact overall wine quality. To add to the complexity,

\footnotetext{
* Corresponding author at: School of Food Science, Washington State University, P.O. Box 646376, Pullman, WA 99164-6376, United States.

E-mail address: cfross@wsu.edu (C.F. Ross).
} 
ratios of 4-EP and 4-EG present in wines vary across wine varietals. Specifically, the 4-EP:EG ratio is dependent upon the wine varietal, with ratios varying from 10:1 for Cabernet Sauvignon, 9:1 for Bordeaux style red wines, and 3.5:1 for Pinot Noir (Curtin et al., 2008; Wedral et al., 2010).

Not only due to differences among wines, the presentation of the complexities of "Brett"-related compounds vary due to the tasters themselves, including their wine expertise and knowledge (Tempère et al., 2014). Although closely related, the terms wine expert and wine knowledge differ when considering types of consumers. While the term "wine expert" generally refers to someone with experience working in the wine industry, wine knowledge is more indicative of a theoreticalbased understanding of wine concepts (Parr, Heatherbel, \& White, 2002; Schiefer \& Fischer, 2008; Tempère et al., 2014). Specifically, winemakers and those holding academic degrees in wine tasting displayed significantly lower detection thresholds of 4-EP and 4-EG compared to winegrowers or those without tasting degrees, indicating higher sensitivity (Tempère et al., 2014). Other studies have defined experience in terms of consumption patterns or wine knowledge (Hopfer \& Heymann, 2014; Schiefer \& Fischer, 2008). Segmenting consumers on wine expertise, wine knowledge, or both represents an important marketing area as wine experts often spend and purchase larger amounts of wine than novices (D'Alessandro \& Pecotich, 2013). In the present study, wine knowledge was assessed using a questionnaire, with the assignment of a low, medium, or high knowledge level made in accordance to the number of correct responses collected from the questionnaire.

The presence of Brettanomyces in a wine is a world-wide issue, and is therefore a great concern to the international wine industry. Specifically, in Portugal of 88 samples of Pinot Noir wines, 57\% contained Brettanomyces (Deavila \& Ayub, 2013). Furthermore, while generally considered undesirable in the United States, consumer preferences and perception may have a cultural underpinning (Wedral et al., 2010). Previous cross-cultural studies have provided insight into consumer variations in preferences on food products including apples, sugar, and caffeine levels (Jaeger, Andani, Wakeling, \& MacFie, 1998; Prescott, 1998). Cross-cultural studies examining wine have primarily focused on variations in wine quality, and determined country-specific factors which may influence the overall judgement of wine quality (Sáenz-Navajas, Ballester, Peyron, \& Valentin, 2014). Furthermore, the globalization of the wine market has resulted in changing consumer trends. New world wines are becoming increasingly popular, with the United States wines expected to have continued international success (Campbell, Campbell, \& Guibert, 2006). Therefore, this study investigating the perceived difference of Brettanomyces volatile phenols on red wine aroma was conducted in two major wine-producing areas, Washington State within the United States, a New World producer, and Portugal, an Old-World producer.

In the present study, a difference from control test was used to identify the magnitude of difference that consumers could detect across five treatment levels of 4-EP, 4-EG, and 4-EC prepared in a commercial red wine. In a difference from control test the size of any existing differences between samples may be assessed. The difference from control method is advantageous in situations in which a difference may be detectable, but the size of the difference affects the decisions and conclusions concerning the research objectives (Meilgaard, Carr, \& Civille, 2006). The wine was the same in both locations so as to minimize the influence of matrix on volatile phenol perception. Treatment levels were selected based upon previously reported threshold values. Furthermore, this study also used the classification of consumers, through demographic responses and wine knowledge to further add to the existing information of the many factors influencing the perception of Brettanomyces aromas.
Table 1

Concentrations of volatile compounds spiked into tested wines.

\begin{tabular}{lllll}
\hline & $\begin{array}{l}\text { 4-Ethylphenol } \\
(\mu \mathrm{g} / \mathrm{L})\end{array}$ & $\begin{array}{l}\text { 4-Ethguiacol } \\
(\mu \mathrm{g} / \mathrm{L})\end{array}$ & $\begin{array}{l}\text { 4-Ethylcatechol } \\
(\mu \mathrm{g} / \mathrm{L})\end{array}$ & $\begin{array}{l}\text { Ratio of } \\
\text { added 4- } \\
\text { EP:4- } \\
\text { EG:4:EC }\end{array}$ \\
\hline Base wine & 0 & 0 & 0 & $0: 0: 0$ \\
Treatment 1 & 250 & 50 & 50 & $5: 1: 1$ \\
Treatment 2 & 500 & 100 & 100 & $5: 1: 1$ \\
Treatment 3 & 1000 & 200 & 200 & $5: 1: 1$ \\
Treatment 4 & 1500 & 300 & 300 & $5: 1: 1$ \\
Treatment 5 & 2500 & 500 & 500 & $5: 1: 1$ \\
\hline
\end{tabular}

\section{Materials and methods}

\subsection{Methods}

4-Ethyphenol (>97\%) was purchased from Fisher Scientific (Hampton, NH) while 4-ethyguiacol $(>98 \%)$ and 4-ethylcatechol ( $>$ 98\%) were purchased from Sigma Aldrich (St. Louis, MO, USA). Reagent water used was purified by Milli-Q (Millipore, Bedford, MA, USA). The filtration unit for purification of deionized water that was used for palate cleansing during the sensory test was purchased from EcoLab (Spokane, WA). In Portugal, 4-ethyphenol ( $>97 \%$ ) was purchased from Fluka Chemie AG (Buchs, Switzerland), while 4-ethyguiacol $(>95 \%)$ and 4-ethylcatechol (> 98\%) were purchased from Tokyo Chemical Industry Co. Ltd. (Tokyo, Japan) and Sigma Aldrich (St. Louis, MO, USA), respectively.

\subsection{Wine treatments}

Concentrations of 4-EP, 4-EG, and 4-EC were spiked into wines at a 5:1:1 ratio, respectively (Table 1 ). These concentrations were selected based on previously published studies as cited in the introduction. Stock solutions of 4-EP $(3 \mathrm{mg} / \mathrm{mL}), 4-\mathrm{EG}(1 \mathrm{mg} / \mathrm{mL})$, and 4-EC $(1 \mathrm{mg} / \mathrm{mL})$ were prepared separately in $10 \%$ ethanol, and added directly to $3 \mathrm{~L}$ of base wine to prepare each treatment. Wine treatments were created 1 day prior to the sensory consumer panel, and were flushed with nitrogen before capping. Wine was stored at $23^{\circ} \mathrm{C}$ until use.

\subsection{Wine analysis}

The base wine was a Piteira 2011 DOC Reserve red wine blend imported from Alentejo, Portugal, with a manufacturer reporting of $14 \% \mathrm{v} / \mathrm{v}$ ethanol. This base wine was characterized using standard wine chemistry measurements (Iland, Bruer, Edwards, Weeks, \& Wilkes, 2004). Specifically, ethanol content was determined using an ebulliometer (Alla France, France). Titratable acidity was measured using a TitroLine Easy Autotitration calibrated with $\mathrm{pH} 4.0$ and 7.0 standards (Schott Instruments, Germany). Wine $\mathrm{pH}$ was measured using a Fischer Scientific Accumet basic AB15 Plus pH meter (Hampton, NH, USA).

To determine the baseline concentration of 4-ethyphenol (4-EP) and 4-ethyguiacol (4-EG) in the base wine, headspace analysis was performed using headspace solid phase microextraction coupled with gas chromatography and mass spectrometry (HS-SPME/GC-MS). This analysis was also repeated on the wine treatments to verify the concentrations of 4-EP and 4-EG present in the wine prior to sensory evaluation. For the determination of 4-EP and 4-EG, a $65 \mu \mathrm{m} \mathrm{SPME}$ fiber coated with polydimethylsiloxane-divinylbenzene (PDMS-DVB) was used (Supelco, Bellefonte, PA). Prior to use, the fiber was conditioned at $250{ }^{\circ} \mathrm{C}$ for $30 \mathrm{~min}$. For each analysis, $4 \mathrm{~mL}$ of wine sample and $1.28 \mathrm{~g} \mathrm{NaCl}$ were placed into a $20 \mathrm{~mL}$ vial that was capped with a crimp seal with a Naturkautschuk PTFE magnetic cap (Gerstel INC., Linthicum, MD). Samples were analyzed using a GC $6890 \mathrm{~N}$ chromatograph coupled with a mass spectrometer (MS 5975) (Agilent 
technologies, Avondale, PA). The following GC column was used, HP5MS (5\%-phenyl-methylpolysiloxane), $30.0 \mathrm{~m} \times 250 \mu \mathrm{m} \times 0.25 \mu \mathrm{m}$ (Agilent Technologies Inc., New Castle, DE). Extraction time was $1 \mathrm{~h}$ and desorption time was $5 \mathrm{~min}$. Helium was used as the carrier gas, and column flow was set at $3.8 \mathrm{~mL} / \mathrm{min}$. 4-EP and 4-EG were identified by mass spectra and the National Institute of Standards and Technology (NIST) mass spectra library provided by the Chemstation software (version E.02.02.1431). Quantification was performed by external standard calibration. Five-point standard curves were constructed for both 4-EP and 4-EG, with concentrations ranging from 125-3125 $\mu \mathrm{g} / \mathrm{L}$ to $25-625 \mu \mathrm{g} / \mathrm{L}$, respectively. The unknown concentration found in the wines was determined from the standard curve by examining peak areas of the two compounds. Analyses were performed in triplicate (Villamore, Evans, Mattinson, \& Ross, 2013).

\subsection{Sensory analysis}

Consumers $(n=121)$ were recruited from Washington State University. Ages ranged from 21 to 79, with a mean age of 35. Of the consumers, 46 were male, 74 were female, and 1 preferred not to answer. Same number of consumers $(n=121)$, with the age ranging from 20 to 70 years, were also recruited from Instituto Superior de Agronomia and some wine companies. Out of 121 consumers, 62 were male and remaining 59 were female. To participate, consumers were required to consume wine at least once or twice a month. At Washington State University, evaluations took place in eight individual booths under white light, while at Instituto Superior de Agronomia, a well-ventilated classroom under white light was used to perform evaluation. Wine samples $(25 \mathrm{~mL})$ were served at $23^{\circ} \mathrm{C}$ in ISO/INAO clear wine glasses. Samples were poured, and covered with a petri dish $1 \mathrm{~h}$ prior to evaluations to allow for equilibration of volatile compounds into the headspace of the glasses. Consumers were provided with deionized water, and were instructed to sniff the water during the $30 \mathrm{~s}$ between samples. Consumers at Instituto Superior de Agronomia filled in their responses using paper ballots, while at Washington State University, data were collected using Compusense Cloud software (Guelph, ON Canada). Following the completion of the panel, consumers were provided with non-monetary incentives.

For both locations, a difference from control test was used for the consumer evaluations. The five wine treatments were presented using a randomized complete block design. Specifically, for each presentation pair, a control sample, labeled ' $C$ ', was presented simultaneously with a spiked sample, labeled with a three-digit code. A total of six pairs, each with a control and treatment, were presented; five of the presentations were evaluating the difference of a treatment to a control sample and one presentation was a blind control. Consumers were forced to take 30 second breaks in between each evaluation to prevent fatigue.

Prior to evaluations, consumers answered several demographic questions. Questions included frequency of consumption of red wine, occasions and locations for consuming wine, and specific varietals usually consumed. Additional questions, on more specific wine consumption behavior included identifying years spent working in the wine industry, job positions held in relation to the industry, and the frequency of participation in wine tastings. Following these questions, consumers were instructed to perform the evaluations using only aroma, and instructed not to taste any of the wine samples. Using a difference from control test, consumers were asked to rate the difference between the pairs of samples presented along a 9-point scale with $1=$ no difference, $2=$ very slight difference, $3=$ slight difference, $4=$ slight $/$ moderate difference, $5=$ moderate difference, $6=$ moderate/large difference, $7=$ large difference, $8=$ very large difference and $9=$ extreme difference. Consumers were informed that the test sample may be the same as the control.

After finishing the difference from control test, consumers answered 12 questions concerning wine and winemaking to ascertain their wine knowledge level (Table 2). These questions were developed using questions from a previous study (Hopfer \& Heymann, 2014), as well as considering suggestions from the researchers. Wine knowledge status was determined by the number of questions correctly answered. A 'low' knowledge level was assigned by answering fewer than 4 questions correctly; a 'medium' status was assigned by answering 5-8 questions correctly, and a 'high' knowledge status was assigned by answering 9 or more questions correctly.

\subsection{Data analysis}

Analysis of variance (ANOVA) was performed for both testing locations to complete segmentation on consumers regarding responses to demographic questions and knowledge level. A two-way ANOVA was performed for panelist and treatments for both testing locations. Tukey's HSD was subsequently used to determine significant differences across expertise levels and wine treatment levels. Mean difference from control for each treatment level for both locations were compared to one another using two-sample $t$-test. At Washington State University, sensory panel data were collected using Compusense Cloud software (Guelph, ON, Canada). At Instituto Superior de Agronomia, sensory panel data were collected using paper ballots. Data from both locations was analyzed using STATA data analysis and statistical software (StataCorp, College Station, TX, 2015).

\section{Results and discussion}

\subsection{Wine chemistry}

The base wine composition was $13.6 \% \mathrm{v} / \mathrm{v}$ ethanol, $0.520 \mathrm{~g} / 100 \mathrm{~mL}$ titratable acidity, pH 3.79. The low levels of 4-EP (27 $\mu \mathrm{g} / \mathrm{L})$ and 4-EG $(7 \mu \mathrm{g} / \mathrm{L})$ detected in the base wine were well below threshold concentrations of $230-650 \mu \mathrm{g} / \mathrm{L}$ and 33-135 $\mu \mathrm{g} / \mathrm{L}$, respectively, suggesting that no Brettanomyces infections were present (Botha, 2010; Francis \& Newton, 2005; Lattey et al., 2010; Nikfardjam et al., 2009; Petrozziello et al., 2014; Suárez et al., 2007; Wedral et al., 2010). Concentrations of 4-EC were not determined, but given that it has lower precursor conversion rates by Brettanomyces compared to 4-EP (Malfeito-Ferreira et al., 2009), it was likely present in undetectable to very low concentrations.

The concentrations of 4-EP of 4-EG in the wine treatment levels, were verified by headspace analysis (Table 3). The average concentrations of 4-EP and 4-EG that likely influence wine flavor and likely wine acceptability are above $620 \mu \mathrm{g} / \mathrm{L}$ and $140 \mu \mathrm{g} / \mathrm{L}$, respectively (Curtin et al., 2008; Wedral et al., 2010). In the current experiment, these concentrations are surpassed when moving from the second treatment, containing $423 \mu \mathrm{g} / \mathrm{L}$ of 4-EP and $93 \mu \mathrm{g} / \mathrm{L}$ of 4-EG to the third treatment containing $935 \mu \mathrm{g} / \mathrm{L}$ and $167 \mu \mathrm{g} / \mathrm{L}$ of 4-EP and 4-EG, respectively.

The perception threshold values of 4-EP and 4-EG are greatly influenced by the matrix of the wine itself (Petrozziello et al., 2014). For example, a reported threshold concentrations of 4-EP in the presence of oak was reported as high as $1000 \mu \mathrm{g} / \mathrm{L}$ (Coulter et al., 2003). Therefore, the concentrations of 4-EP and 4-EG used in this study span a broad range, encompassing levels both above and below reported threshold values. At the lowest level, concentrations of 4-EP and 4-EG were at $250 \mu \mathrm{g} / \mathrm{L}$ and $50 \mu \mathrm{g} / \mathrm{L}$, respectively. Wines considered to be high in "Brett" character have been described as having a 4-EP concentration of $3000 \mu \mathrm{g} / \mathrm{L}$ (Licker, Acree, \& Henick-Kling, 1998). Given the concentrations in the present study of $2500 \mu \mathrm{g} / \mathrm{L}$ 4-EP, and $500 \mu \mathrm{g} / \mathrm{L}$ of 4-EG, the concentrations used in this study were of practical relevance.

For 4-EC, previous findings have reported levels in contaminated wines to range from 4 to $1620 \mu \mathrm{g} / \mathrm{L}$ (Larcher et al., 2008). Concentrations of 4-EC used in this study range from 50 to $500 \mu \mathrm{g} / \mathrm{L}$ and as such, include levels below and above the threshold range of $100-400 \mu \mathrm{g} / \mathrm{L}$ (Botha, 2010; Larcher et al., 2008). 
Table 2

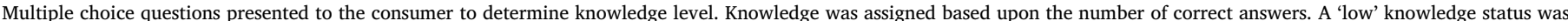

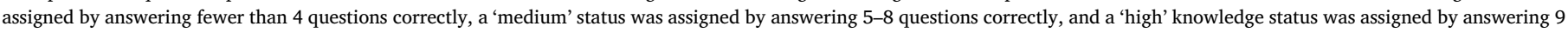
or more questions correctly.

1. Which of the following countries is NOT in the top 4 wine producers in the world?

2. Which of the following grape variety is used for the production of red wine?

3. Most beers contain 3-5\% alcohol. Most completely fermented table wines usually contain how much alcohol?

4. Which of the following grape varieties is one of the varieties used in the production of the famous wines from Bordeaux?

5. Which of the following grape varieties is used for the most famous wines from Argentina?

6. Which of the following is one of the major grape varieties used for the production of wines from the Chianti region in Italy?

7. What does it mean when a wine is "dry"?

8. Which wine(s) are produced without skin maceration?

9. In wine, what does a stuck fermentation refer to?

10. Malolactic fermentation occurs due to the presence of what in a wine?

11. Which two starting materials are needed for a wine to undergo fermentation?

12. Which of the following is not a common material in which to ferment wine?

\section{Table 3}

Headspace solid phase microextraction coupled with gas chromatography and mass spectrometry (HS-SPME/GC-MS) verification of volatile concentrations in the wine treatments. Mean values within a column followed by the same letter are not significantly different $(\mathrm{p} \leq 0.05)$.

\begin{tabular}{lll}
\hline & 4-Ethylphenol $(\mu \mathrm{g} / \mathrm{L})$ & 4-Ethylguiacol $(\mu \mathrm{g} / \mathrm{L})$ \\
\hline Base wine & $27 \mathrm{a}$ & $7 \mathrm{a}$ \\
Treatment 1 & $225 \mathrm{~b}$ & $37 \mathrm{~b}$ \\
Treatment 2 & $423 \mathrm{c}$ & $93 \mathrm{c}$ \\
Treatment 3 & $935 \mathrm{~d}$ & $167 \mathrm{~d}$ \\
Treatment 4 & $1400 \mathrm{e}$ & $280 \mathrm{e}$ \\
Treatment 5 & $2495 \mathrm{f}$ & $558 \mathrm{f}$ \\
\hline
\end{tabular}

\subsection{Consumer population}

Consumers in both the Portugal, and United States locations answered several demographic questions, including how often they consume wine, as well as any time spent working in the wine industry. More than $50 \%$ of the consumers from the United States testing location reported to consume wine at least 2-3 times a week. Of the consumers from the Portugal location, $>40 \%$ reported to consume wine at least 2-3 times a week, as well as $28 \%$ reporting to have spent at least one year working in the wine industry (Table 4). These trends are consistent with research indicating that while consumption of wine is increasing in the United States, consumers may actually be drinking less wine in European countries including France, Italy, and Portugal (Smith \& Mitry, 2007; Thach \& Olsen, 2006).

The influence of the cultural background of the consumer on the detection of Brettanomyces could provide useful context regarding how differences could influence consumer consumption and purchasing behaviors. The consumption of wine is an important aspect of the Southern European lifestyle and culture. In the past several decades,

Table 4

Demographic information and responses from consumers from the United States ( $n=121)$ and Portugal $(n=121)$ difference from control sensory panels.

\begin{tabular}{|c|c|c|c|c|}
\hline \multirow{2}{*}{$\begin{array}{l}\text { Testing } \\
\text { location }\end{array}$} & \multicolumn{4}{|l|}{ Demographic questions } \\
\hline & Mean age \pm SD (years) & Gender & $\begin{array}{l}\text { Wine } \\
\text { consumption } \\
2-3 \text { times a } \\
\text { week or more }\end{array}$ & $\begin{array}{l}\text { Worked in } \\
\text { the wine } \\
\text { industry } \\
\text { for } 1 \text { year } \\
\text { or more }\end{array}$ \\
\hline Portugal & $35 \pm 13^{\mathrm{a}}$ & $\begin{array}{l}\text { Male: } 62 \\
\text { Female:59 }\end{array}$ & $48^{\mathrm{b}}$ & 34 \\
\hline $\begin{array}{l}\text { United } \\
\qquad \begin{array}{l}\text { Stat- } \\
\text { es }\end{array}\end{array}$ & $35 \pm 13$ & $\begin{array}{l}\text { Male: } 46 \\
\text { Female: } 74 \\
\text { Prefer not } \\
\text { to answer: } \\
1\end{array}$ & 71 & 8 \\
\hline
\end{tabular}

${ }^{\mathrm{a}} \mathrm{n}=111$.

${ }^{\mathrm{b}} \mathrm{n}=113$.
Portugal has been one of the world's 12 leading wine producing countries (Silva, Figueiredo, Hogg, \& Sottomayor, 2014). Although Portugal has a longer history concerning wine production and consumption, New World countries, including the United States, have increased their presence in the global wine market (Anderson, 2004). Specifically, the millennial generation of the United States has been considered to be the largest consumer group in the history of the United States, and are already consuming more quantities of wine than their previous generation (Thach \& Olsen, 2006). While the high percentage of United States consumers from this study who drink wine at least 2-3 times a week agrees with the rise of New-World producers, consumption behaviors, and involvement does not have a direct relationship with consumer wine knowledge. Being more involved with wine, whether through consumption patterns or a having a general interest in wine may not equate to have the technical competence seen in expert wine quality evaluations (Schiefer \& Fischer, 2008).

\subsection{Sensory evaluation}

In the present study, a difference from control test was used to identify the magnitude of difference detectable by consumers across five treatment levels of 4-EP, 4-EG, and 4-EC in a commercial red wine. For each location, the mean difference from control for each treatment level was determined. Following this analysis, results were compared for the United States and Portugal testing locations.

The United States and Portugal locations both rated a blind control, where identical samples of base wine were presented (Fig. 1). The United States reported a mean difference from control of 3.26 for the blind control while Portugal reported a difference of 3.20 . Both values corresponded to a 'slight' difference on the 9-point scale. The values that were reported were significantly lower than the differences reported between the control and any of the treatment samples. While a response of 'no difference' would

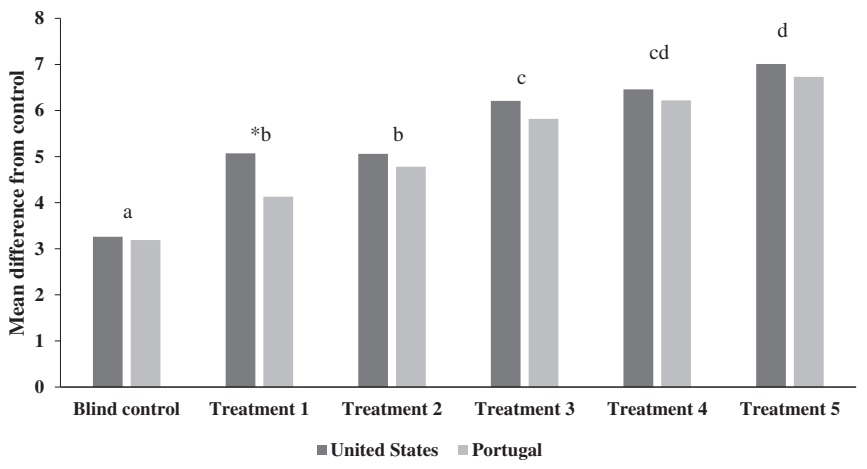

Fig. 1. Difference from control results across wine treatment levels (shown in Table 1) for United States $(n=121)$ and Portugal consumer panels $(n=120)$. Difference from control was measured used a 9-point scale where $1=$ no difference, $5=$ moderate difference and $9=$ extreme difference. Across treatments, mean values followed by the different letters are significantly different $(\mathrm{p} \leq 0.05)$. An asterisk indicates significant difference between the two locations. 
normally be expected for two identical samples, previous investigations on the placebo effect suggest otherwise. Even when samples are identical and the ballot indicates this may be the case, many consumers will give false preferences to one sample over another due to the preconception that two samples must be different (Lawless \& Heymann, 2010; Villegas-Ruiz, Angulo, \& O'Mahony, 2008).

For the United States location, the first and second treatments were not significantly different from one another in their comparison to the control sample $(p \geq 0.05)$. The consumers in the United States gave both the first and second treatments a difference value from the control corresponding to a 'moderate difference' at 5.07 and 5.06, respectively. The third and fourth treatments were significantly different from the second treatment, with mean differences of 6.21 and 6.46, respectively. The largest mean difference from control for United States consumers was for treatment 5 at 7.01, corresponding to a 'large difference' (Fig. 1). This treatment contained the highest concentrations of the three volatile compounds.

Portuguese consumers had a mean difference from control of 4.13 for the first treatment, and 4.77 for the second treatment. The third and fourth treatments, at 5.82 and 6.22, respectively, were significantly different from the second treatment. The final treatment with the largest mean difference of 6.73 related to a moderate to large difference between the two samples (Fig. 1).

The magnitude of difference between treatments two and three was the largest difference between two consecutive treatment levels for both locations, and encompasses previously published threshold ranges of 4-EP at $230-650 \mu \mathrm{g} / \mathrm{L}$ and 4-EG at 22-135 $\mu \mathrm{g} / \mathrm{L}$ (Lattey et al., 2010; Nikfardjam et al., 2009; Petrozziello et al., 2014; Suárez et al., 2007; Wedral et al., 2010). Concentrations of 4-EP increased from $500 \mu \mathrm{g} / \mathrm{L}$ (treatment 2) to $1000 \mu \mathrm{g} / \mathrm{L}$ (treatment 3), while concentrations of 4-EG increased from $100 \mu \mathrm{g} / \mathrm{L}$ to $200 \mu \mathrm{g} / \mathrm{L}$. The increase of 4-EC from $100 \mu \mathrm{g} / \mathrm{L}$ (treatment 2) to $200 \mu \mathrm{g} / \mathrm{L}$ (treatment 3) encompassed the threshold range of $100-400 \mu \mathrm{g} / \mathrm{L}$ that, when present, resulted in a significantly altered aroma profile (Larcher et al., 2008).

For both locations, the highest treatment level had the largest difference from control. This was to be expected as the levels of 4-EP $(2500 \mu \mathrm{g} / \mathrm{L})$ and 4-EG $(500 \mu \mathrm{g} / \mathrm{L})$ were above reported threshold ranges of $230-650 \mu \mathrm{g} / \mathrm{L}$ and $22-135 \mu \mathrm{g} / \mathrm{L}$, respectively (Lattey et al., 2010; Nikfardjam et al., 2009; Petrozziello et al., 2014; Suárez et al., 2007; Wedral et al., 2010). A wide threshold range has been reported for 4 EC, with reported values including $60 \mu \mathrm{g} / \mathrm{L}$ and 100-400 $\mu \mathrm{g} / \mathrm{L}$ (Hesford et al., 2004; Larcher et al., 2008). As such, the highest treatment level of $500 \mu \mathrm{g} / \mathrm{L}$ would be above threshold. Considering all three metabolites exceeded threshold values, the high difference from control values of 7.01 and 6.73 for the United States and Portugal, respectively coincide with the influence of 4-EP, 4-EG, and 4-EC on the alteration of red wine aroma (Kheir, Salameh, Strehaiano, Brandam, \& Lteif, 2013; Larcher et al., 2008; Romano et al., 2009).

\subsection{Influence of cultural differences}

The mean values from the difference from control for each treatment was compared across the two locations (Fig. 1). When comparing treatment 1 to the control, consumers from the United States had a significantly higher mean difference compared to consumers from the Portugal location ( $\mathrm{p} \leq 0.05$ ). From these results, variations between the two populations were seen in their ability to discern differences in wine containing 4-EP, 4-EG and 4-EC. The perception of wines containing Brettanomyces metabolites, depends on several factors, one of which has suggested to be differences in cultural preferences. One study examining the sensory properties of Brettanomyces provided further insight to cultural differences arising from terms used to describe Brettanomyces metabolites. While an international group of wine evaluators use more neutral terms such as burnt plastic and phenolic to describe Brettanomyces aromas, evaluators from the United States (specifically New York) used terms including cow manure, barnyard and horse sweat (Wedral et al., 2010). Brettanomyces can cause consumer rejection of the wine; however, the first step to evaluating consumer rejection is determining consumer detection. Therefore, in the present study, differences reported between the mean difference from control values at the first level may support implications of cultural variations affecting the perception of Brettanomyces aromas.

Specific traditions, beliefs, and values of a society shape wine consumption patterns (Do, Patris, \& Valentin, 2009). In the evaluation of wine quality, a cross-cultural study comparing French and Spanish wine consumers determined that consumer knowledge, involvement, and nationality of consumers were all good predictors of wine quality perception (Sáenz-Navajas et al., 2014). Additional cross-cultural comparisons of New and Old World wine producing countries resulted in similar conclusions in reporting a relationship between culture and the social representations of wine (Mouret, Lo Monaco, Urdapilleta, \& Parr, 2013; Sáenz-Navajas et al., 2014). For example, consumers from France, an Old-World wine country, associated wine with aspects of national identity, while New Zealand consumers, a New-World country, associated wine consumption with work and passion (Mouret et al., 2013).

With many Western countries placing a greater importance on the global marketing and consumer driven product development, considering variations across cultures on their food choices, and consumption patterns delivers beneficial information (Prescott, Young, O'neill, Yau, \& Stevens, 2002). Both similarities and differences have been reported in cross-cultural comparisons of wine quality and consumption behaviors (Mueller, Remaud, \& Chabin, 2011). Country-specific effects, as collected from cross-cultural studies tend to provide useful segmentation strategies, as seen in the present study from the variances in the perceived difference between consumers from the United States and Portugal of Brettanomyces aromas at the first treatment level.

\subsection{Influence of wine knowledge}

Knowledge levels are presented in Table 5. Of the 119 consumers (2 consumers didn't fill datasheet) from Portugal, 41 were classified as having a 'low' wine knowledge, 42 were classified as 'medium', and 36 were classified as having a 'high' wine knowledge. Of the 121 United States consumers, 61 were classified as having a 'low' knowledge level, 48 as 'medium' and 12 as having a 'high' wine knowledge. There is a potential for bias in cross-cultural analysis due to a greater number of 'high' knowledge consumers from the Portugal testing location. This may be a result of more consumers being involved in the wine industry as seen in Table 4.

Segmenting the consumers based on their wine knowledge, the mean difference from control was determined for each wine knowledge level at all treatment levels. For the United States consumers, no significant differences were found among the three knowledge levels in their evaluation of the wines (Table 6).

However, wine knowledge had a significant effect on the difference from control values for Portuguese consumers (Table 7). Consumers in the medium or high knowledge levels reported a significantly higher mean for treatment 2 and treatment 5 compared to those in the low knowledge group. Specifically, at treatment 2, the low knowledge group reported a significantly lower difference from control (3.83) in

\section{Table 5}

Knowledge status distribution from questionnaire responses for United States $(n=121)$ and Portugal $(n=119)$ consumer panels.

\begin{tabular}{llll}
\hline Expertise Level & Correctly answered & United States & Portugal \\
\hline Low & $1-4$ & 61 & 41 \\
Medium & $5-8$ & 48 & 42 \\
High & $9-12$ & 12 & 36 \\
\hline
\end{tabular}


Table 6

Difference from control results across wine treatment levels based on wine knowledge level of consumers from the United States location $(n=121)$. Difference from control was measured used a 9-point scale where $1=$ no difference, $5=$ moderate difference and $9=$ extreme difference.

\begin{tabular}{llll}
\hline \multirow{2}{*}{ Sample } & \multicolumn{2}{l}{ Knowledge level } & \\
\cline { 2 - 4 } & Low & Medium & High \\
\hline Blind control & 3.67 & 2.96 & 2.42 \\
Treatment 1 & 5.11 & 4.94 & 5.41 \\
Treatment 2 & 5.16 & 4.73 & 5.83 \\
Treatment 3 & 6.12 & 6.13 & 7.00 \\
Treatment 4 & 6.36 & 6.33 & 7.50 \\
Treatment 5 & 6.89 & 7.02 & 7.67 \\
\hline
\end{tabular}

Table 7

Difference from control results across wine treatment levels based on wine knowledge level of consumers from the Portugal location $(n=119)$. Difference from control was measured used a 9-point scale where $1=$ no difference, $5=$ moderate difference and $9=$ extreme difference. Within a row, mean values followed by the same letter are not significantly different $(\mathrm{p} \leq 0.05)$.

\begin{tabular}{llll}
\hline Sample & \multicolumn{2}{l}{ Knowledge level } & \\
\cline { 2 - 4 } & Low & Medium & High \\
\hline Blind control & $3.44 \mathrm{a}$ & $3.48 \mathrm{a}$ & $2.61 \mathrm{a}$ \\
Treatment 1 & $3.78 \mathrm{a}$ & $4.45 \mathrm{a}$ & $4.14 \mathrm{a}$ \\
Treatment 2 & $3.83 \mathrm{a}$ & $4.95 \mathrm{~b}$ & $5.69 \mathrm{~b}$ \\
Treatment 3 & $5.53 \mathrm{a}$ & $5.67 \mathrm{a}$ & $6.31 \mathrm{a}$ \\
Treatment 4 & $5.78 \mathrm{a}$ & $6.64 \mathrm{a}$ & $6.31 \mathrm{a}$ \\
Treatment 5 & $5.90 \mathrm{a}$ & $6.95 \mathrm{~b}$ & $7.50 \mathrm{~b}$ \\
\hline
\end{tabular}

comparison to the medium and high knowledge groups at 4.95 and 5.69 , respectively. Ethylphenol concentrations in the second treatment were $500 \mu \mathrm{g} / \mathrm{L}$ for 4-EP, and $100 \mu \mathrm{g} / \mathrm{L}$ for 4-EG and 4-EC, with each concentration being just below or near reported concentrations that influence wine flavor (Curtin et al., 2008; Larcher et al., 2008; Wedral et al., 2010).

Differences between the wine knowledge levels agrees with a previous study in which winemakers and those holding academic degrees in wine tasting show a greater ability in their discrimination capacities of 4-EP and 4-EG. When presented with concentrations ranges of $3.44-3455 \mu \mathrm{g} / \mathrm{L}$ of $4-\mathrm{EP}$ and $0.4-396 \mu \mathrm{g} / \mathrm{L}$ of $4-\mathrm{EG}$, winemakers and those holding tasting degrees could detect lower concentrations of these two compounds than winegrowers or those without tasting degrees, suggesting greater sensitivity (Tempère et al., 2014). The larger difference from control values for the medium and high knowledge level when 4-EP, 4-EG, and 4-EC were present in relatively low concentrations support implications of a greater sensory ability for those with specific knowledge or those considered to be wine experts (Schiefer \& Fischer, 2008; Tempère et al., 2014).

The use of a questionnaire has effectively been applied to investigate differences among consumers and experts on their ratings of wine quality and liking (Hopfer \& Heymann, 2014; Schiefer \& Fischer, 2008). One study examining differences among consumers and experts on their ratings of wine quality for several Riesling wines showed that consumers with more wine knowledge, as determined by a questionnaire, rated wines more similarly to experts. Using a tasting procedure resembling that applied in quality competitions, consumers and experts rated wines along a three-point scale ranging from bronze to gold. For the greater number of questions correctly answered on the questionnaire, consumers rated wines more similarly to experts using the bonze to gold scale. Furthermore, the relationship between consumers' rating ability in comparison to experts was dependent on both wine experience, in terms of long-lasting practical tasting experience, as well as wine knowledge (Schiefer \& Fischer, 2008). In the present study, segmenting consumers using a questionnaire proved to be an effective tool when assessing consumer evaluations on Brettanomyces aromas, and warrants further investigation as to the complexities of wine expertise on sensory abilities.

Consumers and wine experts vary in their evaluations of wine. Previous research suggests that those less experienced with wine, or novices, form their judgments using a more holistic evaluation, while experts use a more detailed approach and consider relationships among perceived attributes (Ballester, Patris, Symoneaux, \& Valentin, 2008; Perrouty, d'Hauteville, \& Lockshin, 2006). Similarly, by having a deeper understanding of wine styles, expert wine consumers may focus on the individual features that differentiate wine samples. A study on the aroma of Chardonnay and Melon de Bourgone varieties demonstrated how experts have a well-defined and common mental representation of the aroma of the two varietals, while novices had less organization in their assessments. Furthermore, a greater ability in discrimination of wines has been suggested for expert consumers (Ballester et al., 2008). In the present study, the significant differences in the difference from control values for Portuguese consumers at the low level in comparisons to those in the medium or high knowledge levels, coincide with the suggestion of a greater discrimination ability.

Further studies on consumer knowledge, and expertise demonstrated how sweetness preferences vary between groups. More experienced wine drinkers and winemakers prefer Semillon wine with lower levels of added glucose in comparison to those with less wine experiences, who prefer sweeter wines (Blackman, Saliba, \& Schmidtke, 2010). Wine liking and consumption behaviors are also influenced by expertise levels, with again more experienced consumers showing an increased liking for red and dry white wines, thus supporting this preference of experts for lower sweetness (Pickering, Jain, \& Bezawada, 2014). To this end, consumer knowledge, experience, and involvement in the wine industry alter the perception of wine. In the present study, the perception of wine, specifically containing Brettanomyces metabolites was determined to be influenced by wine knowledge, and may therefore encourage further investigation to aid wine producers and retailers in identifying current wine sensory preferences (Melo, Delahunty, \& Cox, 2011).

\section{Conclusions}

Brettanomyces is one of the many yeasts associated with wine spoilage that can alter the sensory properties of wine. This study assessed similarities and differences in consumers from the United States and Portugal on their detection of three Brettanomyces volatile compounds. Consumers from Portugal and the United States distinguished between the blind control and all treatment levels, demonstrating consumer's ability to detect differences in wine aroma due to the presence of 4-EP, 4-EG, and 4-EC. For both locations, the increase in the level of difference from the control was the greatest between treatment $2(500 \mu \mathrm{g} / \mathrm{L}$ 4-EP) to treatment 3 ( $1000 \mu \mathrm{g} / \mathrm{L}$ 4-EP) which corresponded to reported detection threshold ranges of 4-EP, 4-EG, and 4-EC. In support of previous findings on the effect of wine knowledge on wine evaluations, the medium and high knowledge levels for Portuguese consumers had significantly higher difference from control values for two treatments. The effects cultural variations and wine knowledge have on the detection of Brettanomyces could provide useful context on how differences could influence consumer consumption and purchasing behaviors

\section{Authorship declaration}

All authors have contributed significantly and are in agreement with the manuscript.

\section{Acknowledgement}

We are indebted to Mr. José Piteira of Amareleza Vinhos for supplying commercial wine bottles, and to Mr. Domingos Soares Franco of 
José Maria da Fonseca for handling bottle shipment from Portugal to USA. Part of the research was supported by the funds of the LEAF Research Center of the FCT (Portuguese National Research Foundation) (UID/AGR/04129/2013). M. C. is a recipient of a postdoc FCT grant (SFRH/BPD/70888/2010).

\section{References}

Anderson, K. (2004). The world's wine markets: Globalization at work. Cheltenham, UK; Northampton, MA, USA: Edward Elgar Publishing.

Ballester, J., Patris, B., Symoneaux, R., \& Valentin, D. (2008). Conceptual vs. perceptual wine spaces: Does expertise matter? Food Quality and Preference, 19, 267-276.

Blackman, J., Saliba, A., \& Schmidtke, L. (2010). Sweetness acceptance of novices, experienced consumers and winemakers in Hunter Valley Semillon wines. Food Quality and Preference, 21, 679-683.

Botha, J. J. (2010). Sensory, chemical and consumer analysis of Brettanomyces spoilage in South African wines (PhD Dissertation). South Africa: Department of Chemistry and Polymer Science, Stellenbosch University (150 pp).

Campbell, G., Campbell, G., \& Guibert, N. (2006). Introduction: Old World strategies against New World competition in a globalising wine industry. British Food Journal, 108, 233-242.

Chatonnet, P., Dubourdieu, D., Boidron, J. N., \& Pons, M. (1992). The origin of ethylphenols in wines. Journal of Science and Food Agriculture, 60, 165-178.

Coulter, A., Robinson, E., Cowey, G., Francis, I. L., Lattey, K., Capone, D. L., ... Godden, P. W. (2003). Dekkera/Brettanomyces yeast - An overview of recent AWRI investigations and some recommendations for its control. In S. M. Bell, K. A. de Garis, C. G. Dundon, R. P. Hamilton, S. J. Partridge, \& G. S. Wall (Eds.), Proceedings of a seminar. Grapegrowing at the edge. Managing the wine business. Impacts on wine flavour; 10-11 July 2003; Tanunda, SA, Australia (pp. 41-50). Glen Osmond, SA, Australia: Australian Society of Viticulture and Oenology.

Curtin, C., Bramley, B., Cowey, G., Holdstock, M., Kennedy, E., Lattey, K., ... Godden, P. (2008). Sensory perceptions of 'Brett' and relationship to consumer preference. In R. J. Blair, P. J. Williams, \& I. S. Pretorius (Eds.), Proceedings of the Australian wine industry technical conference; 28 July-2 August 2007; Adelaide, SA, Australia (pp. 207211). Glen Osmond, SA, Australia: Australian Wine Industry Technical Conference.

D'Alessandro, S., \& Pecotich, A. (2013). Evaluation of wine by expert and novice consumers in the presence of variations in quality, brand and country of origin cues. Food Quality and Preference, 28, 287-303.

Deavila, L., \& Ayub, M. (2013). Occurrence of Brettanomyces/Dekkera in Brazilian red wines and its correlation with ethylphenols. Brazilian Journal of Microbiology, 44(1).

Do, V.-B., Patris, B., \& Valentin, D. (2009). Opinions on wine in a new consumer country: A comparative study of Vietnam and France. Journal of Wine Research, 20, 253-271.

Francis, I., \& Newton, J. (2005). Determining wine aroma from compositional data. Australian Journal of Grape and Wine Research, 11, 114-126.

Fugelsang, K. C., \& Edwards, C. G. (2006). Wine microbiology: Practical applications and procedures. New York, NY, USA: Springer.

Hesford, F., Schneider, K., Porret, N., \& Gafner, J. (2004). Identification and analysis of 4ethyl catechol in wine tainted by Brettanomyces off-flavor. American Journal of Enology and Viticulture, 55, 304A.

Hopfer, H., \& Heymann, H. (2014). Judging wine quality: Do we need experts, consumers or trained panelists? Food Quality and Preference, 32, 221-233.

Iland, P., Bruer, N., Edwards, G., Weeks, S., \& Wilkes, E. (2004). Chemical analysis of grapes and wine: Techniques and concepts. Campbelltown, SA, Australia: Patrick Iland Wine Promotions.

Jaeger, S. R., Andani, Z., Wakeling, I. N., \& MacFie, H. J. (1998). Consumer preferences for fresh and aged apples: A cross-cultural comparison. Food Quality and Preference, 9, 355-366.

Kheir, J., Salameh, D., Strehaiano, P., Brandam, C., \& Lteif, R. (2013). Impact of volatile phenols and their precursors on wine quality and control measures of Brettanomyces/ Dekkera yeasts. European Food Research and Technology, 237, 655-671.

Larcher, R., Nicolini, G., Bertoldi, D., \& Nardin, T. (2008). Determination of 4-ethylcatechol in wine by high-performance liquid chromatography-coulometric electrochemical array detection. Analytica Chimica Acta, 609, 235-240.

Lattey, K. A., Bramley, B. R., \& Francis, I. L. (2010). Consumer acceptability, sensory properties and expert quality judgements of Australian Cabernet Sauvignon and Shiraz wines. Australian Journal of Grape and Wine Research, 16, 189-202.

Lawless, H. T., \& Heymann, H. (2010). Sensory evaluation of food: Principles and practices. New York, NY, USA: Springer.

Licker, J. L., Acree, T. E., \& Henick-Kling, T. (1998). What is 'Brett' (Brettanomyces) flavor?: A preliminary investigation. In A. L. Waterhouse, \& S. E. Ebeler (Eds.),
Chemistry of wine flavor (pp. 96-115). Washington D.C., USA: American Chemical Society.

Loureiro, V., \& Malfeito-Ferreira, M. (2006). Spoilage activities of Dekkera/Brettanomyces spp. In C. Blackburn (Ed.), Food spoilage microorganisms (pp. 354-398). Cambridge: Woodhead Publishers Chapter 13.

Malfeito-Ferreira, M. (2011). Yeasts and wine off-flavours: A technological perspective. Annals of Microbiology, 61, 95-102.

Malfeito-Ferreira, M., Barata, A., \& Loureiro, V. (2009). Wine spoilage by fungal metabolites. In C. Polo, \& M. V. Moreno-Arribas (Eds.), Wine chemistry and biochemistry (pp. 615-645). New York: Springer Chapter 11.

Meilgaard, M. C., Carr, B. T., \& Civille, G. V. (2006). Sensory evaluation techniques (5th ed.). Florida: CRC press.

Melo, L., Delahunty, C., \& Cox, D. N. (2011). A new approach using consumers' 'drinking histories' to explain current wine acceptance. Food Research International, 44, 3235-3242.

Mouret, M., Lo Monaco, G., Urdapilleta, I., \& Parr, W. V. (2013). Social representations of wine and culture: A comparison between France and New Zealand. Food Quality and Preference, 30, 102-107.

Mueller, S., Remaud, H., \& Chabin, Y. (2011). How strong and generalisable is the Generation Y effect? A cross-cultural study for wine. International Journal of Wine Business Research, 23, 125-144.

Nikfardjam, M. P., May, B., \& Tschiersch, C. (2009). 4-Ethylphenol and 4-ethylguaiacol contents in bottled wines from the German 'Württemberg' region. European Food Research and Technology, 230, 333-341.

Parr, W. V., Heatherbel, D., \& White, K. G. (2002). Demystifying wine expertise: Olfactory threshold, perceptual skill and semantic memory in expert and novice wine judges. Chemical Senses, 27, 747-755.

Perrouty, J. P., d'Hauteville, F., \& Lockshin, L. (2006). The influence of wine attributes on region of origin equity: An analysis of the moderating effect of consumer's perceived expertise. Agribusiness, 22, 323-341.

Petrozziello, M., Asproudi, A., Guaita, M., Borsa, D., Motta, S., Panero, L., \& Bosso, A. (2014). Influence of the matrix composition on the volatility and sensory perception of 4-ethylphenol and 4-ethylguaiacol in model wine solutions. Food Chemistry, 149, 197-202.

Pickering, G., Jain, A., \& Bezawada, R. (2014). Segmentation and drivers of wine liking and consumption in US wine consumers. International Journal of Wine Research, 6, 9-19.

Prescott, J. (1998). Comparisons of taste perceptions and preferences of Japanese and Australian consumers: Overview and implications for cross-cultural sensory research. Food Quality and Preference, 9, 393-402.

Prescott, J., Young, O., O'neill, L., Yau, N., \& Stevens, R. (2002). Motives for food choice: A comparison of consumers from Japan, Taiwan, Malaysia and New Zealand. Food Quality and Preference, 13, 489-495.

Romano, A., Perello, M.-C., Lonvaud-Funel, A., Sicard, G., \& de Revel, G. (2009). Sensory and analytical re-evaluation of 'Brett character'. Food Chemistry, 114, 15-19.

Sáenz-Navajas, M.-P., Ballester, J., Peyron, D., \& Valentin, D. (2014). Extrinsic attributes responsible for red wine quality perception: A cross-cultural study between France and Spain. Food Quality and Preference, 35, 70-85.

Schiefer, J., \& Fischer, C. (2008). The gap between wine expert ratings and consumer preferences. International Journal of Wine Business Research, 20, 335-351.

Silva, P. A., Figueiredo, I., Hogg, T., \& Sottomayor, M. (2014). Young adults and wine consumption a qualitative application of the theory of planned behavior. British Food Journal, 116, 832-848.

Smith, D. E., \& Mitry, D. J. (2007). Cultural convergence: Consumer behavioral changes in the European wine market. Journal of Wine Research, 18, 107-112.

Suárez, R., Suárez-Lepe, J. A., Morata, A., \& Calderón, F. (2007). The production of ethylphenols in wine by yeasts of the genera Brettanomyces and Dekkera: A review. Food Chemistry, 102, 10-21.

Tempère, S., Cuzange, E., Schaaper, M. H., de Lescar, R., de Revel, G., \& Sicard, G. (2014). "Brett character" in wine: Is there a consensus among professional assessors? A perceptual and conceptual approach. Food Quality and Preference, 34, 29-36.

Thach, E. C., \& Olsen, J. E. (2006). Market segment analysis to target young adult wine drinkers. Agribusiness, 22, 307-322.

Villamore, R. R., Evans, M. A., Mattinson, D. S., \& Ross, C. F. (2013). Effects of ethanol, tannin, and fructose on the headspace concentration and potential sensory significance of odorants in a model wine. Food Research International, 50, 38-45.

Villegas-Ruiz, X., Angulo, O., \& O'Mahony, M. (2008). Paired preference "placebo" tests with "identical" stimuli: Does introducing graded preference responses affect the frequency of "no preference" responses? Journal of Sensory Studies, 23, 439-449.

Wedral, D., Shewfelt, R., \& Frank, J. (2010). The challenge of Brettanomyces in wine. LWT Food Science and Technology, 43, 1474-1479. 